Military Technical College Kobry El-Kobba

Cairo, Egypt

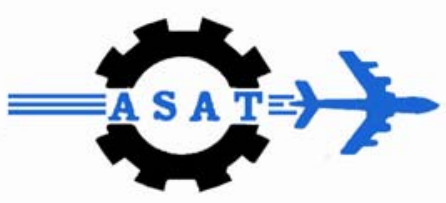

12-th International Conference

on

Aerospace Sciences \&

Aviation Technology

\title{
THE MECHANISM OF HARDENING FOR MARAGING 300 STEEL
}

\author{
I. NEDELCU*, Irina CARCEANU*, G. COSMELEATA ${ }^{* * *}$, I. ROCEANU ${ }^{* * *}$
}

\begin{abstract}
Maraging steels are characterised by ultra-high strength due to the precipitate formed during ageing. Development of new maraging steels has drawn much attention from civil and military industry, targeting for specific applications. Maraging steels work well in electro-mechanical components where ultra-high strength is required, along with good dimensional stability during heat treatment.

Several desirable properties of maraging steels are: ultra-high strength at room temperature; good weldability ; section size is an important factor in the hardening process; simple heat treatment, which results in minimum distortion;superior fracture toughness compared to quenched and tempered steel of similar strength level ;low carbon content, which precludes decarburization problems.

These factors indicate that maraging steels could be used in applications such as shafts, and substitute for long, thin, carburized or nitrided parts, and components subject to impact fatigue, such as print hammers or clutches.

The study has been conducted on samples which have been placed in solutions with different cooling speeds (water, air) and then subjected to the thermal treatments for precipitation until the apparition of the austenite.
\end{abstract}

\section{KEY WORDS}

Hardening by precipitation; maraging steels; thermal treatments.

\footnotetext{
* Senior Researcher, Dpt. Of Metallurgical Work, Prelucrari Metalurgice Ltd., Bucharest, Romania

** Dr. Eng. Scientific Researcher, Dpt. Of Special Alloys - Sintered Products, Metallurgical Research Institute, Bucharest, Romania

*** Professor Dr. Eng., Dpt. Of Materials Science, POLITEHNICA University, Bucharest, Romania

**** Professor Dr.Lt. Col., Dpt of the Advanced Distributed Learning , "Carol I" National Defence University, Bucharest, Romania
} 


\section{INTRODUCTION}

The recent rapid development of this type of steel is due to an assembly of higly important properties such as: high mechanical resistance, with remarkable ductility and tenacity; simple thermic treatments; good weldability; criogenic resistance; easily deformable and processable. [1, 2, 3]

In the case of usual hardenable steel utilized in the car construction industry, the process of hardening results in the formation of a hard and fragile martensite, which shall in turn be reannealed to obtain desired mechanical characteristics. In the case of MARAGING steel on the other hand, hardening results in the formation of a soft, ductile martensite, with a high content in nickel and very little carbon. The high mechanical characteristics are obtained through an ageing treatment due to the precipitation of some complex intermetallic phases.

Furthermore, the technology of fabrication of small pieces with high resistance, using conventional steel, is far more complicated and expensive than that of small pieces with high tenacity made out of maraging steel. Consequently, the advantages acquired by the usage of this type of steel are both technic and economic. [4]

An important limitation concerning the production of conventional high-resistance steel is represented by the association between the deformations and fragile crackings. The higher the mechanical resistance, the more fragile is the type of cracking at high solicitations.

Carbon is the main element which confers the high resistance but in the same time the fragile character of steel, which is why the actual tendency regarding the development of high-resistance alloys is to dramatically lower the contained carbon. On the other hand, a very low percent of carbon $(<0,03 \%)$ needs to be associated with a martensitic, soft and massive structure, and with hardening by ageing. And this is actually how the name of "maraging" came into play. The development of maraging steel emerged from the $\mathrm{Fe}-\mathrm{Ni}$ binary alloy, with a percent of Ni ranging between 18 and 25 . This results in a massive martensite if air-cooled. The equilibrium diagram for $\mathrm{Fe}-\mathrm{Ni}$ is illustrated in Fig. 1.

This martensite does not contain carbon as it is the case with usual Fe-C steel, it is not modified tetragonally, having a regulated cubic shape. It is called $\alpha_{0}$ solid solution, having the same chemical composition like the austenite it resulted from.

For practical necesities, a real metastable diagram of $\mathrm{Fe}-\mathrm{Ni}$ alloys can be utilized (Fig.2), which presents thermic histeresis.

The elements for alloying selected after $\mathrm{Ni}$ have been $\mathrm{Mo} \sim 5 \%$ and $\mathrm{Ti} \sim 1 \%$. Applying an ageing treatment in the $450-500{ }^{\circ} \mathrm{C}$ interval has lead to the formation of the following precipitates: $\mathrm{Ni}_{3} \mathrm{Mo}$ or $\mathrm{Ni}_{3}(\mathrm{Mo}, \mathrm{Ti}) \mathrm{Ni}_{3} \mathrm{Ti}$ or $\mathrm{Fe}_{7} \mathrm{Mo}_{6}$. Excess titanium neutralizes carbon by forming carbon carbide. This alloying had a suplimentary effect: lowering the point of martensitic MS and MF transformation. 
The following element introduced in maraging steel was Co. Its effect is significant for the formation of a high-resistance and high-tenacity alloy by lowering the solubility of Mo in Fe (solid solution $\alpha$ ), consequently leading to the formation of more precipitates, which in turn results in the increase of the martensitic MS and MF transformation temperatures.

Other potential alloying elements are $\mathrm{Al}, \mathrm{Nb}, \mathrm{Zr}, \mathrm{Be}, \mathrm{W}, \mathrm{V}, \mathrm{Cu}$, Ta. These are substitution elements which produce the hardening. The normal thermic treatment cycle for MARAGING Co-Mo-Ni steel, laminated or forged, consists of a solubilization reannealing at $820^{\circ} \mathrm{C}$ with air-cooling followed by an ageing treatment for the martensite (maraging) at $480^{\circ} \mathrm{C}$ or $450^{\circ} \mathrm{C}$ with air-cooling.

At the temperature of $820^{\circ} \mathrm{C}$ the phase transformation takes place $(\alpha \Rightarrow \gamma)$, as well as the recrystallization of the austenite and the dissolution of the precipitates. After the cooling at $820^{\circ} \mathrm{C}$, regardless of the speed, the $\gamma \Rightarrow \alpha^{\prime}$ transformation takes place (austenite-martensite).

The hardening of Maraging steel is obtained by the thermic ageing treatment, a period in which the formation of the intermetallic precipitates in the martensitic mass takes place. $[5,13,16,17,18]$.

The highly reduced variation of dimensions during the thermic treatment is remarkable $(0.06-0.08 \%$ when placing in solution and $0.04 \%$ when ageing). This reduced variation of the dimensions allows the processing of the pieces at finite quotas prior to the final ageing treatment.

With the purpose of improving the features of warm-deformability another thermic treatment of partial austenitizing is conducted, at a temperature of about $650^{\circ} \mathrm{C}$. There is poor reference in the specialized literature regarding the necessity of this thermic treatment. Air-cooling facilitates the technologic process of the thermic treatment, both when placing in solution and when ageing ( Fig.3a).

This excellent complex of mechanical and technological features is due to hardening by precipitation of a series of intermetallic compounds in the special martensitic mass ( lath martensite).

The specialty literature states different views concerning the hardening mechanism (precipitation) as well as the different phases of the intermetallic compounds. Therefore, for the process of germination (nucleation) in the ageing reaction, there are two accepted theories: - precipitation by classic germination [6]; - precipitation by spinodal decomposing [7].

There are two types of mechanisms responsible for the hardening of the precipitates, which are implied in the movement of the dislocations: - a looping mechanism [8,9]; a shearing mechanism [10,11], and the reannealed austenite. 
There are numerous opinions of various researchers regarding the types of precipitates emerged at the thermic ageing treatment. Therefore, these determinations include precipitated phases such as [17]: $\mathrm{Y}-\mathrm{Ni}_{3} \mathrm{Mo}[6,10], \eta-$ $\mathrm{Ni}_{3} \mathrm{Ti}[6,13,14]$, laves phases $\mathrm{Fe}_{2} \mathrm{Mo}[6,10], \sigma-\mathrm{FeMo}[6], \mu-\mathrm{Fe}_{7} \mathrm{Mo}_{6}[6,13]$, FeTi $[6,15], \mathrm{Fe}_{2} \mathrm{Ti}[6]$ and the dispersed austenite[16].

In the hereby project we shall attempt to identify by means of electronic microscopy the types of precipitates which appear after the classical cycle of thermic treatment $820^{\circ} \mathrm{C} / 1$ hour/air ( placing in solution) and ageing at $480^{\circ} \mathrm{C} / 3$ hours/air, and to analyze considering the shape, dimensions and the distance between precipitates, the main hardening mechanism.

\section{EXPERIMENTAL WORK}

For the experimentation, a charge of maraging 300 steel was ellaborated, by double vacuum remelting (which implies vacuum induction and arc in vacuum remelting). The ingot weighs $40 \mathrm{~kg}$ and has the diameter $\varnothing 120 \mathrm{~mm}$. The chemical composition of the obtained ingot is presented in Table 1.

Table 1. Chemical composition of the obtained ingot

\begin{tabular}{|r|r|r|r|r|r|r|r|r|r|}
\hline $\mathrm{C}$ & $\mathrm{Si}$ & $\mathrm{Mn}$ & $\mathrm{P}$ & $\mathrm{S}$ & $\mathrm{Al}$ & $\mathrm{C}$ & $\mathrm{Ni}$ & $\mathrm{Mo}$ & $\mathrm{Ti}$ \\
\hline 0,028 & 0,05 & 0,08 & 0,007 & 0,005 & 0,077 & 9,3 & 18,8 & 4,6 & 0,36 \\
\hline
\end{tabular}

The utilized materials for the ellaboration were ARMCO steel, electrolytic nickel, molybdenum and pure titanium, Al 99,995\%. The forging has been done on pneumatic forging hammer from $\varnothing 120$ to $\varepsilon \cdot \mathrm{mm}$ and then to $r \cdot \mathrm{mm}$.

The performed thermic treatments have been as follows:

1. Placing in solution at $820^{\circ} \mathrm{C}$, maintaining for 1 hour, air-cooling followed by water-cooling;

2. Ageing treatment at the following temperatures: $400^{\circ} \mathrm{C}, 420^{\circ} \mathrm{C}, 440{ }^{\circ} \mathrm{C}$, $480^{\circ} \mathrm{C}, 500^{\circ} \mathrm{C}$, the ageing interval being 3 hours;

3. Ageing treatment at $480^{\circ} \mathrm{C}$ with maintaining durations of: $0,1 \mathrm{~h} ; 0,5 \mathrm{~h} ; 1 \mathrm{~h} ; 3 \mathrm{~h}$; $5 \mathrm{~h} ; 7 \mathrm{~h} ; 9 \mathrm{~h}$.

The samples for the traction test have been ellaborated in accordance with ASTM $\mathrm{E9}$, having a calibrated area of $6,25 \mathrm{~mm}$, and the resilience samples have been made with a $V$ canal having dimensions of $10 \times 10 \times 55 \mathrm{~mm}$.

For the structural analysis thermally treated (at $820^{\circ} \mathrm{C} / 1$ hour/air and $480^{\circ} \mathrm{C} / 3$ hours/air) samples have been used. Out of the $r \cdot \mathrm{mm}$ bar, cylindric samples have been prelevated, with a size of $3 \mathrm{~mm}$ and a length of $50-70 \mathrm{~mm}$. The final thinning has been accomplished by electrolytic polishing. 


\section{OBTAINED RESULTS AND INTERPRETATION}

\section{The Effect of the Cooling Method after Austenitizing (air and water)}

There have not been any significant effects noticed, regarding the influence of the cooling speed on the final mechanical features after conducting the thermal ageing treatment at $480^{\circ} \mathrm{C} / 3$ hours/air.

It is remarkable that when air cooling after the treatment for solubility, in the martensitic structure there remains an important amount of austenite of approximately $3 \%$, which means the precipitation has not taken place. This austenite $(\mathrm{\gamma})$ at the next ageing treatment shall transform in reannealed stable austenite $\left(\mathrm{Y}^{\prime}\right)$.

\section{The Influence of the Ageing Temperature on the Mechanical Characteristics}

The initial thermal treatment of the bars has been: placing in solution at $820^{\circ}$ $\mathrm{C} / 1$ hour/air. The results of the mechanical trials that have been conducted are presented in Table 2.

Table 2-The results of the trials regarding the influence of the ageing temperature on the mechanical properties

\begin{tabular}{|c|c|c|c|c|c|c|}
\hline No. & Stamping & $\begin{array}{c}\text { Ageing } \\
\text { temperature }\end{array}$ & $\begin{array}{c}\mathrm{R}_{\mathrm{p} 0.2} \\
\mathrm{~N} / \mathrm{mm}^{2}\end{array}$ & $\begin{array}{c}\mathrm{R}_{\mathrm{m}} \\
\mathrm{N} / \mathrm{mm}^{2}\end{array}$ & $\begin{array}{c}\mathrm{Z} \\
\%\end{array}$ & $\begin{array}{c}\mathrm{KCV} \\
\mathrm{J} / \mathrm{cm}^{2}\end{array}$ \\
\hline 1 & $33 ; 43$ & 400 & 1701 & 1773 & 46 & 25 \\
\hline 2 & $34 ; 44$ & 420 & 1769 & 1836 & 44 & 26 \\
\hline 3 & $35 ; 45$ & 440 & 1814 & 1858 & 43 & 23 \\
\hline 4 & $36 ; 46$ & 460 & 1840 & 1882 & 44 & 22 \\
\hline 5 & $37 ; 47$ & 480 & 1842 & 1913 & 41 & 22 \\
\hline 6 & $38 ; 48$ & 500 & 1772 & 1830 & 43 & 20 \\
\hline
\end{tabular}

By analyzing the data shown in Table 2, the conclusion to be drawn is the increase of the mechanical characteristics along with the ageing temperature whilst maintaining a constant ageing interval (3 hours). The maximum of the resistance characteristics is obtained within the range of $480^{\circ} \mathrm{C} \pm 10^{\circ} \mathrm{C}$. at lower temperatures of precipitation ( $400-440^{\circ} \mathrm{C}$ ), the mechanical resistances, $R_{m}$ and $R_{p 0.2}$ are lower but associated with higher plasticity values $(\mathrm{Z})$ and tenacity values $(\mathrm{KCV})$ than in the case of the improvement at $480^{\circ} \mathrm{C}$.

The acquired results confirm that the mechanisms of precipiting at lower temperatures are slow, leading to fine precipitations of intermetallic compounds in the martensitic matrix, which are responsible for the lower resistance features and higher tenacity. 
The slight tenacity gain accomplished by ageing at $400-440^{\circ} \mathrm{C}$, with the price of an important loss in mechanical resistance compared to ageing at $480^{\circ} \mathrm{C}$ does not justify the ageing treatment al lower temperatures. The optimal association of resistance and tenacity properties is accomplished at temperatures of approximately $480^{\circ} \mathrm{C}$ with a maintaining duration of 3 hours.

\section{The Influence of the Ageing Maintaining Duration (Precipitation) on the Resistance at Cracking and on Hardness}

The results of the determinations are presented in Table 3 and the graphical representation of the influence of maintaining at ageing on hardness is illustrated in Fig. 3b.

Table 3. The experimental results regarding the influence of the ageing duration on hardness and resistance to cracking

\begin{tabular}{|c|c|c|c|c|}
\hline No. & Stamping & $\begin{array}{c}\text { Ageing } \\
\text { duration } \\
\text { (hours) }\end{array}$ & $\begin{array}{c}\text { Hardness } \\
\text { HRC }\end{array}$ & $\begin{array}{c}\text { Resistance to } \\
\text { cracking } \mathrm{R}_{\mathrm{m}} \\
\mathrm{N} / \mathrm{mm}^{2}\end{array}$ \\
\hline 1 & $53 ; 63$ & 0.1 & 38.2 & 1463 \\
\hline 2 & $54 ; 64$ & 0.5 & 45.4 & 1704 \\
\hline 3 & $55 ; 65$ & 1.0 & 50.5 & 1862 \\
\hline 4 & $56 ; 66$ & 3.0 & 53.0 & 1953 \\
\hline 5 & $57 ; 67$ & 5.0 & 52.0 & 1914 \\
\hline 6 & $68 ; 68$ & 7.0 & 53.2 & 1905 \\
\hline 7 & $59 ; 69$ & 9.0 & 53.0 & 1940 \\
\hline 8 & $61 ; 71$ & 11.0 & 53.0 & 1895 \\
\hline
\end{tabular}

NOTE: The initial hardness of the samples after thermal treatment by placing in solution at $820^{\circ} \mathrm{C} / 1$ hour/air has varied between $29-32 \mathrm{HRC}$.

By analyzing the results, one can easily observe the fast increase of the hardness proportional with the maintaining duration, subsequently demonstrating the high precipitation speed (the maraging reaction). Consequently, after maintaining at $480^{\circ}$ $\mathrm{C}$ for 6 minutes, the hardness increased from approximately $32 \mathrm{HRC}$ to $38.2 \mathrm{HRC}$.

The precipitation processes combined with hardening are more intense during the initial periods of time, whilst for higher maintaining durations, the increases are minimal and have a tendency towards lowering.

\section{The Mmicrostructural Analysis}

The investigations of the studied steel's microstructure after the treatments of placing in solution $\left(820^{\circ} \mathrm{C} / 1\right.$ hour/air $)$ and of ageing $\left(480^{\circ} \mathrm{C} / 3\right.$ hours/air) have been effectuated by scanning electronic microscopy (SEM) and transmission electronic microscopy (TEM). 
The results of the micro structural analysis effectuated on Maraging 300 steel samples are shown in Fig. 4, 5, 5a, 5b. The structure of the material is constituted of martensite with fine granulation with finely contoured grain limits. These limits are identical to the limits of the former austenite grains.

In Fig. 5, 5a and 5b for the same sample in the same micro zone as in Fig. 5, the distribution of the compounds rich in nickel is presented, by $\mathrm{XNiK}_{a}$ rays (Fig.5a), while the distribution of the compounds rich in molybdenum by $\mathrm{XMoL}_{\alpha}$ rays is presented in Fig.5b.

Both the nickel and molybdenum compounds have an uniform repartition within the field, within obviously greater nickel density.

The identification of the types of precipitates has been possible at more than $10000 \mathrm{X}$ magnifying. The samples thinned by electrolysis have been investigated by means of TEM. The microstructure of the Maraging steel which was studied is presented in Fig.6, in an image TEM magnified 10500:1 and in Fig.7 magnified 21000:1. One can observe the boundaries between the former austenitic grains and fine martensite needles with a diameter of 0,5-1 $\mu \mathrm{m}$.

Also in Fig. 8 magnified 13500:1, one can observe the existence of a cubic-shaped precipitate with a diameter of approximately $2 \mu \mathrm{m}$. The EDAX micro structural analysis has identified the existence of titanium nitride.

At over 100000:1 magnification, the substructure of individual martensite needles can be identified. For example in Fig.9 the TEM image in luminescent field, at magnification of $160000: 1$, indicates the fact that the substructure consists of very fine precipitates inside the matrix, with an interface between the martensite needles. The identification of the precipitates has been accomplished by TEM images in dark field. By using images in dark field on the same micro zone the $\mathrm{Ni}_{3} \mathrm{Mo}$ phase is identified, with an orthorhombic network (spot 211), Fig.10. Also in Fig.11, realized in dark field, the tetragonal sigma phase has been identified (spot 022).

In Fig.12a the diffraction image is shown, with spots corresponding to both the matrix and to the precipitates, according to the index in Fig. 12. The precipitates have been identified as being an orthorhombic phase $\mathrm{Ni}_{3} \mathrm{Mo}$ and a tetragonal SIGMA phase. The matrix's zone ax is [311], that of the $\mathrm{Ni}_{3} \mathrm{Mo}$ compound is [120], and that of the SIGMA phase is [211].

In Fig. 10 there is the TEM image in dark field corresponding to the spot [211] of the $\mathrm{Ni}_{3} \mathrm{Mo}$ phase, and in Fig.11, the dark field image corresponding to the spot [022] of the phase which demonstrates the uniform distribution of these very small precipitates in the martensitic matrix. The SIGMA phase corresponds to the FeTi precipitate, according to specialists.

The TEM images in Fig.13 present the microstructures of other martensite needles, at superior magnifications. In Fig.13, realized in luminescent field at magnification of 
120000:1, a high density of needle-like precipitates can be identified, but also o high density of dislocations as well as the interface between two needles of martensite. The image in Fig.14 realized in dark field, magnification 120000:1 shows the presence of the $\mathrm{Ni}_{3} \mathrm{Mo}$ precipitates, with orthorhombic structure (spot 211).

\section{CONCLUSIONS}

The microstructure of the studied steel (Maraging 300) after conducting the thermal treatments (placing in solution and ageing) consists of lath martensite with a high density of dislocations.

Based on this martensitic structure, which lacks tetragonal structuring, with ageing, depending on temperature and maintaining duration, the precipitation of the intermetallic phases takes place, and consequently the hardening according to an Orowan mechanism.

The spheric precipitates formed, with sizes between 2-4 nm, determine the moving dislocations to form loops (looping) or shears (shearing), which implies a significant increase of the mechanical resistance from the solution-included state to the precipitated state, with the preservation of high tenacity characteristics.

Our determinations showed two types of precipitated phases as follows: - an orthorhombic $\gamma-\mathrm{Ni}_{3}$ Mo phase; - a tetragonal $\sigma$ - FeMo phase.

\section{REFERENCES}

[1] Decker, R.F., Bash, I.T., Goldman A.J. - ASM Trans Quaterly, 1964, nr. 55, pp.58-76;

[2] Dennis, W.H. - Maraging steels - Iron and steel, may 1968;

[3] Decker, R.F., Bash, I.T., Goldman A.J. - Maraging nikel-cobalt-molybdeum steels, Rev. ASM Trans Quaterly, 1962:55;

[4] Castagne, I.L., Cazin, Y. - Development d'acier maraging a haute resistence Revue de Metallurgie, ian. 1969 ;

[5] Bourgeot, I - Durcissement par revenue des martensites Fe-Ni-Mo et FeNiCoMo, Les Mem. La Metalurgie, 2, 1973.

[6] Floreen S. - Metall. Rev. , 1968, vol. 126(13), pp. 115-28;

[7] Zhanli Guo, Wei Sha - Materials Transaction, vol. 43, no. 6 (2002), pp. 12731282 ;

[8] Vasudervan, V.K., Kim, S.J., Wayman, C.M. - Metalls. Trans. A, 1990, vol. 21A, pp. 2655-2668;

[9] Sinha, P.P., Tharian, K.T. - Mater. Sci. Technol, 1998, vol.14, pp1-9; 
[10] Viswanathan, U.K., Dey, G.K., Asundi, M.K. - Metall. Trans. A, 1993, vol.24A, pp.2429-2442;

[11] Floreen S., Decker, R.F. - ASM Trans. Q., 1962, vol.55, pp.518-530;

[12] Pampillo, C.A., Paxton, H.W. - Metall. Trans., 1972, vol.3, pp.2895-2903;

[13] Sha, W, Cerezo, A., Smith, G.D.W. - Metall. Trans.A, 1993, vol.24A, pp.12211232;

[14] Tewari, R., Mazumdev, S., Batra, I.S., Dey, G.K., Banerjec, S. - Acta Mater., 2000, vol. 48, pp. 1187-1200;

[15] Spitzing, W.A., Chilton, J.M., Barton, C. J. - ASM Trans.Q, 1968, vol.61, pp.635-639;

[16] Thomas, G., Cheng, I., Mihalisin, J.R. - ASM Trans. Q, 1969, vol.62, pp.852857 ;

[17] Yi-He, Ke Yang, Wei Sha - Metall. Trans. A, vol.36A, september 2005, pp. 2273-2287; 


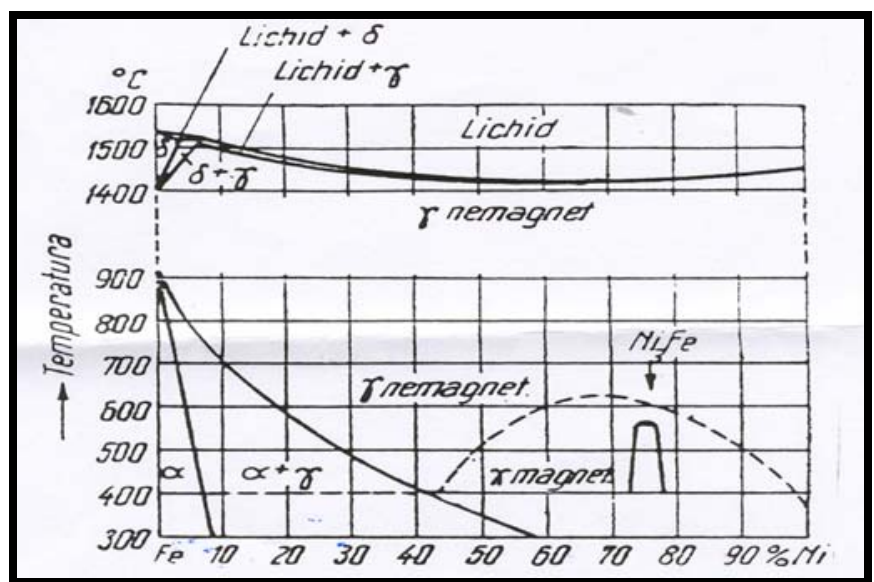

Fig.1. The Fe-Ni equilibrium diagram



Fig.2. Real metastable diagram of Fe-Ni alloys, the side of Fe.

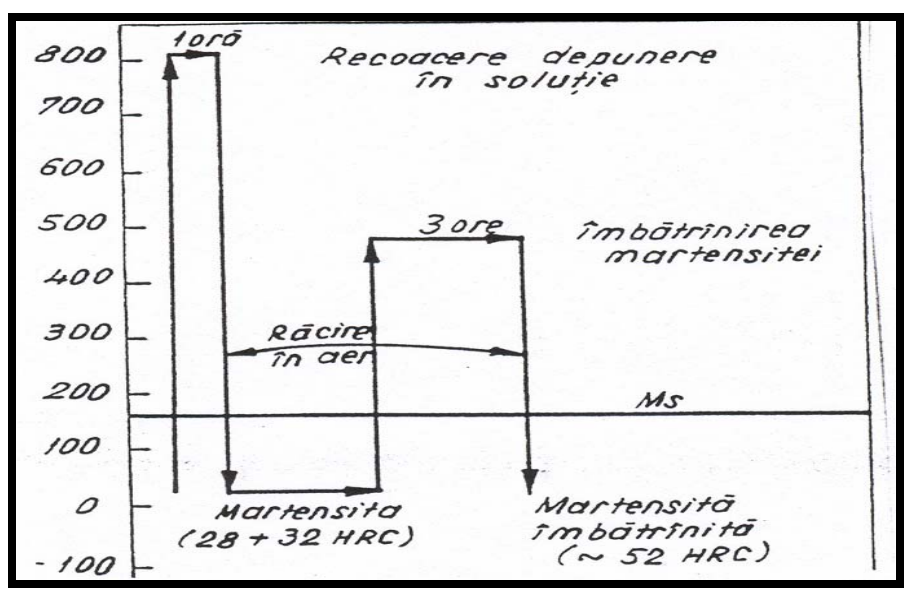

Fig.3a The typical cycle of thermic treatment for „maraging” steel 18\% Ni-CoMo (Decker, Yeo, Eashe Bieber) 


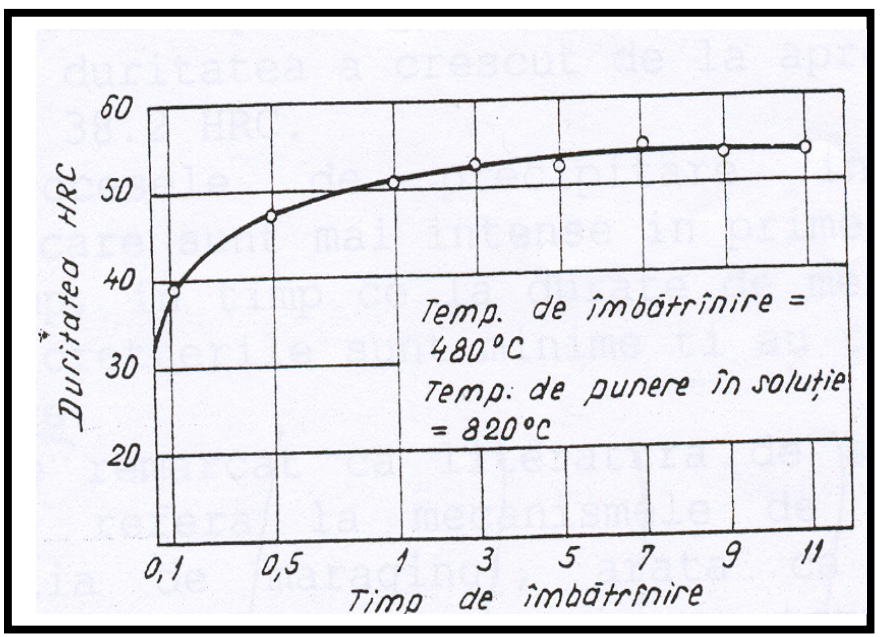

Fig. 3b. The influence of maintaining at ageing on toughness

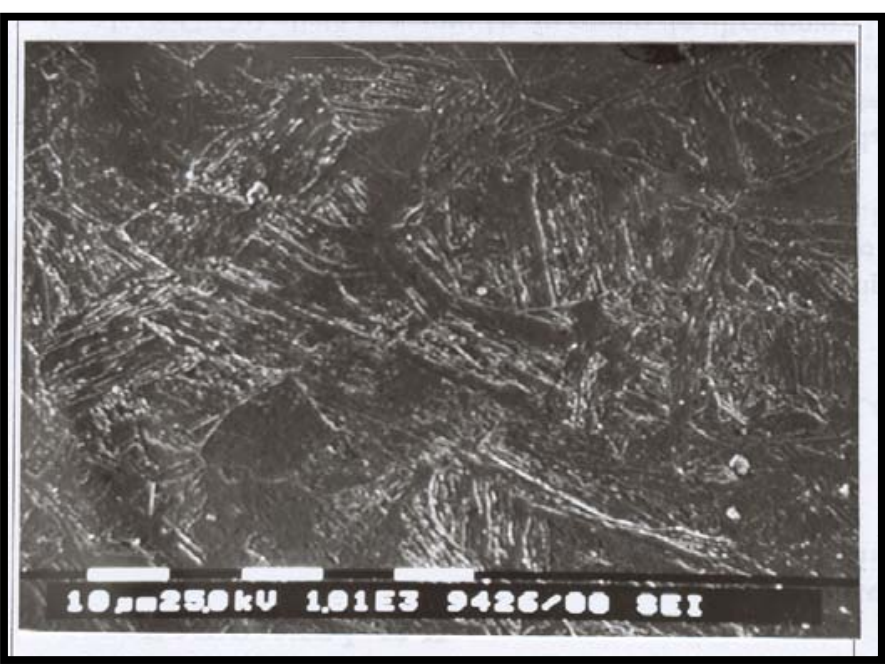

Fig. 4. Secondary electrons image SEI 10000:1

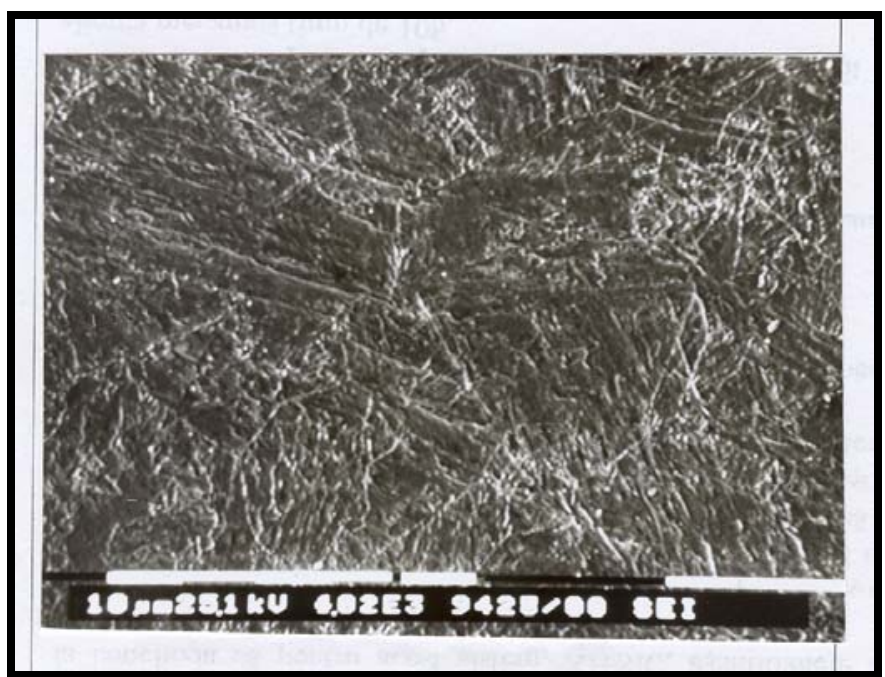


Fig. 5. Secondary electrons image from the micro structure of the sample SEI 4020:1

Fig. 5a The image of the distribution of $X$ NiKa rays corresponding to the micro zone in Fig. 5

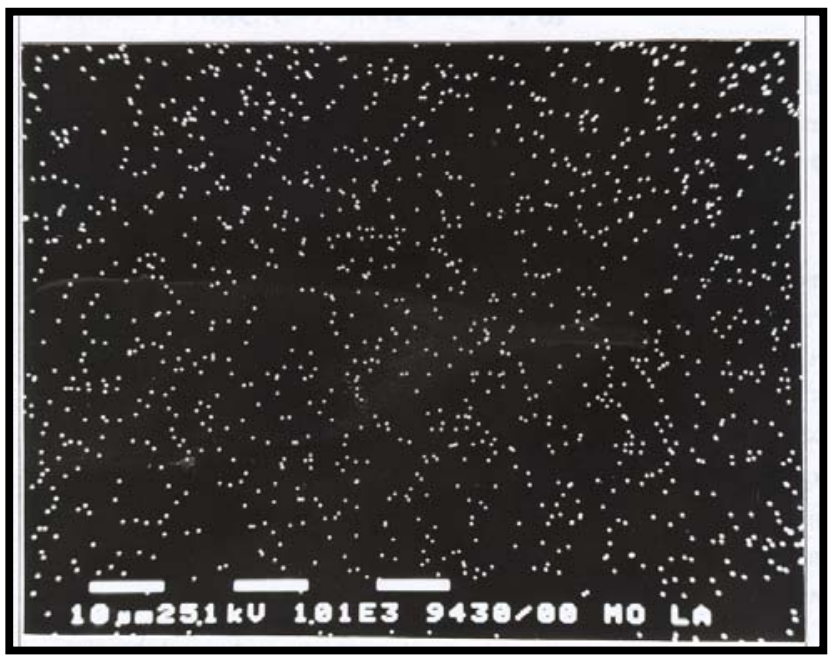

Fig. $5 b$ The image of the distribution of $X$ MoLa rays corresponding to the micro zonein Fig. 5

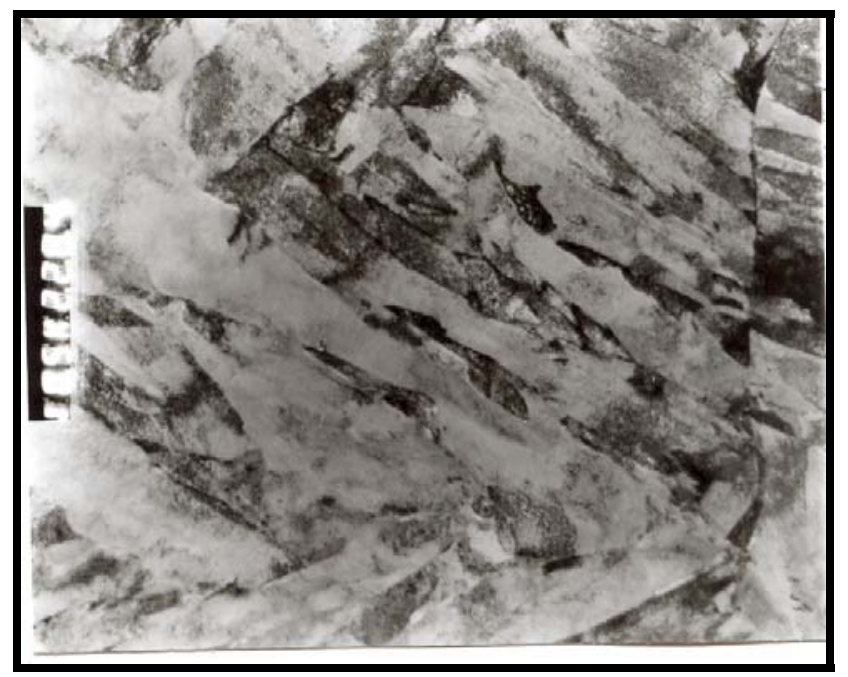

Fig.6. TEM image in luminescent field, 10500:1 


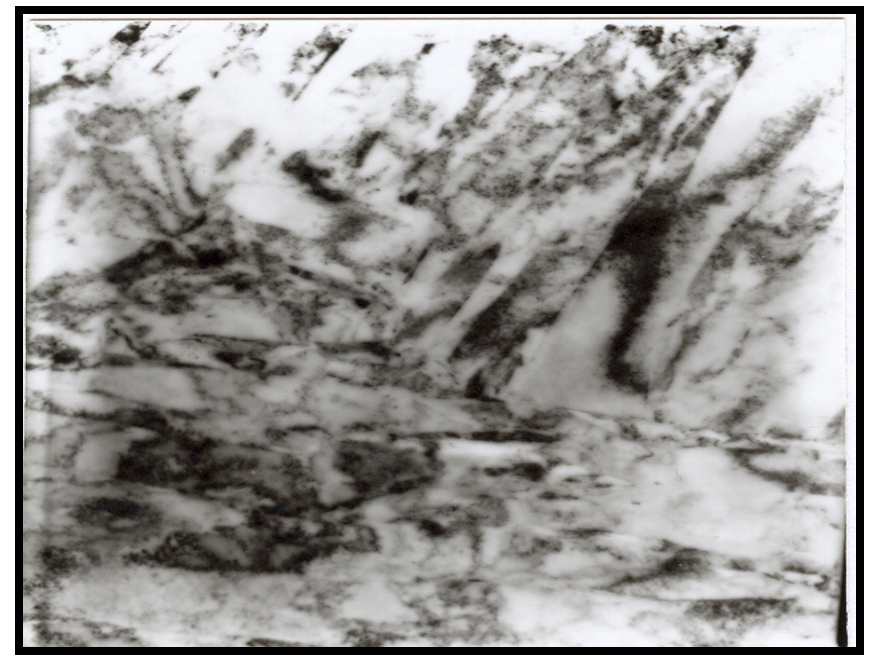

Fig.7. TEM image in luminescent field, 21000:1

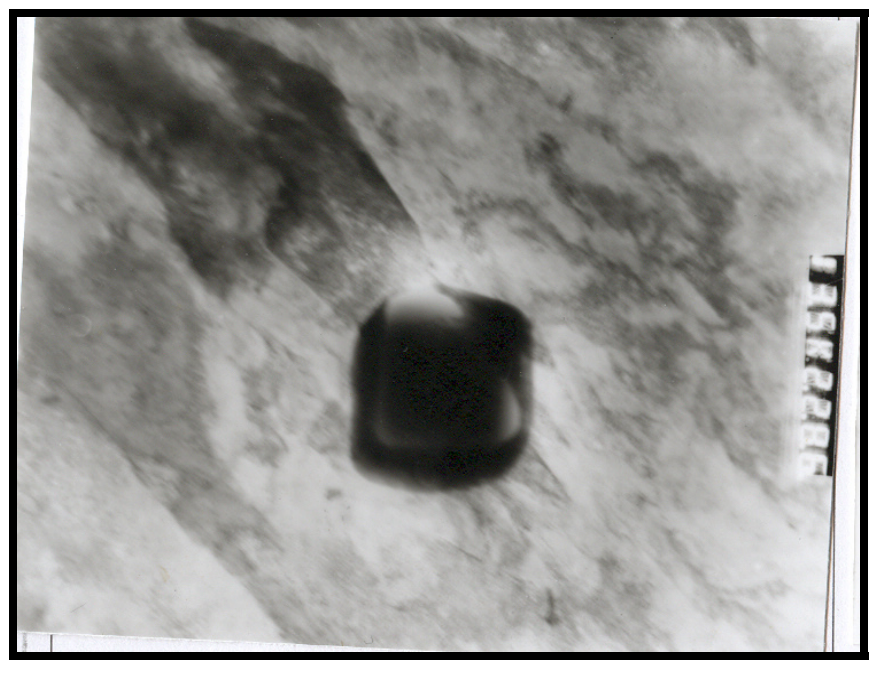

Fig.8. TEM image in luminescent field, 13500:1

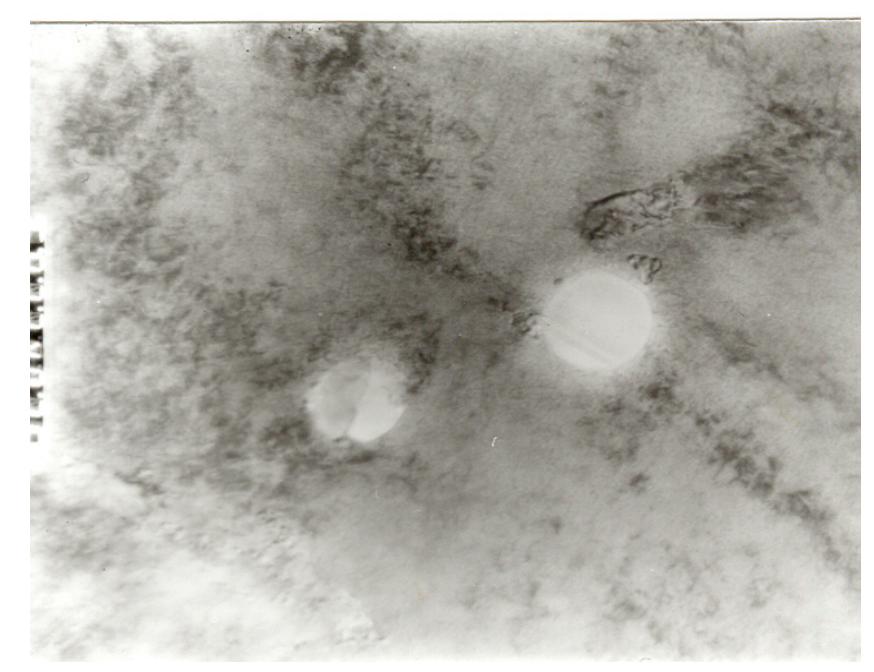


Fig.9.TEM image in luminescent field, 160000:1-The martensite and spherical precipitates

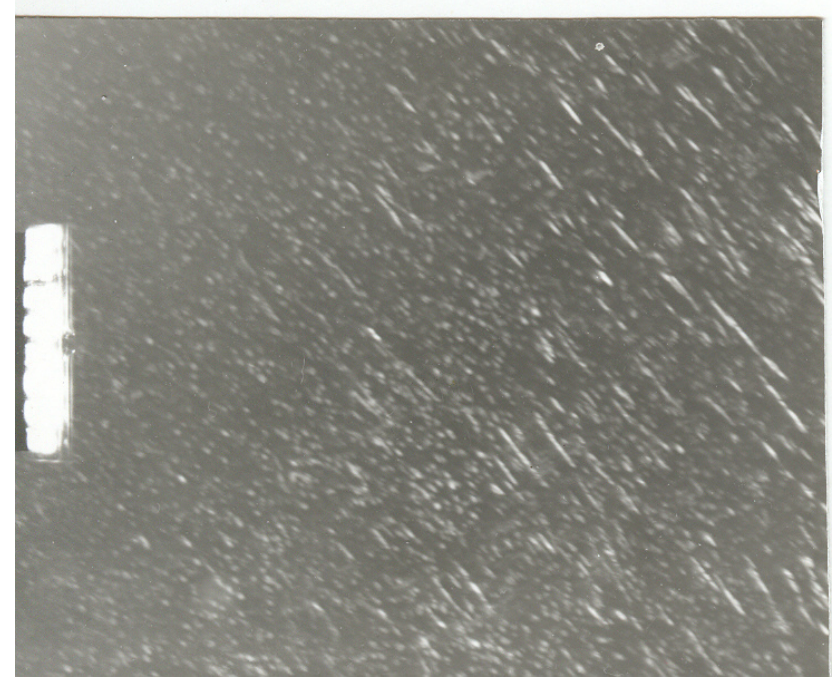

Fig.10 TEM image in dark field, 160000:1-Orthorhombic phase $\mathrm{Ni}_{3} \mathrm{Mo}$, spot (211)

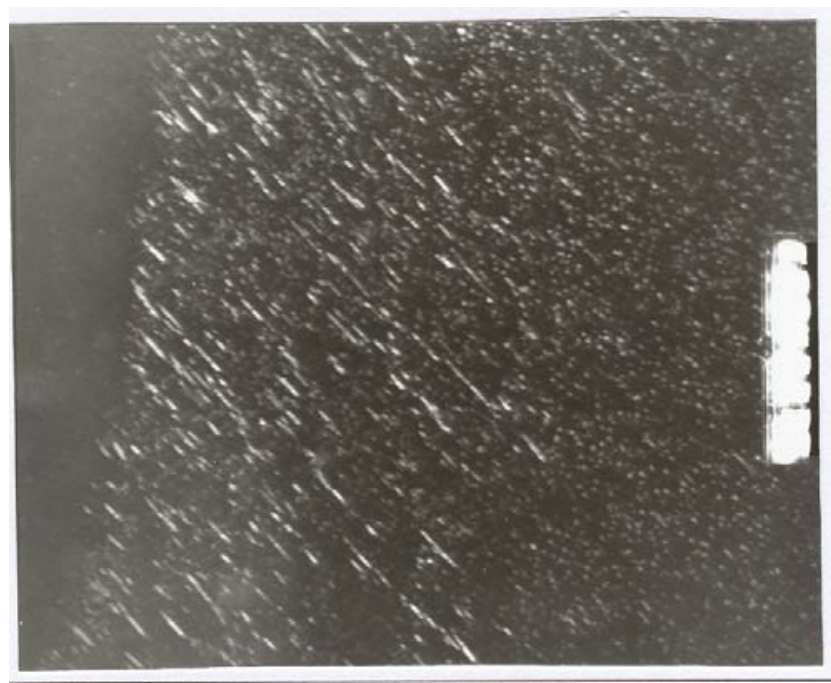

Fig. 11 TEM image in dark field, 160000:1-Tetragonal SIGMA phase $\mathrm{Ni}_{3} \mathrm{Mo}$, spot (022) 


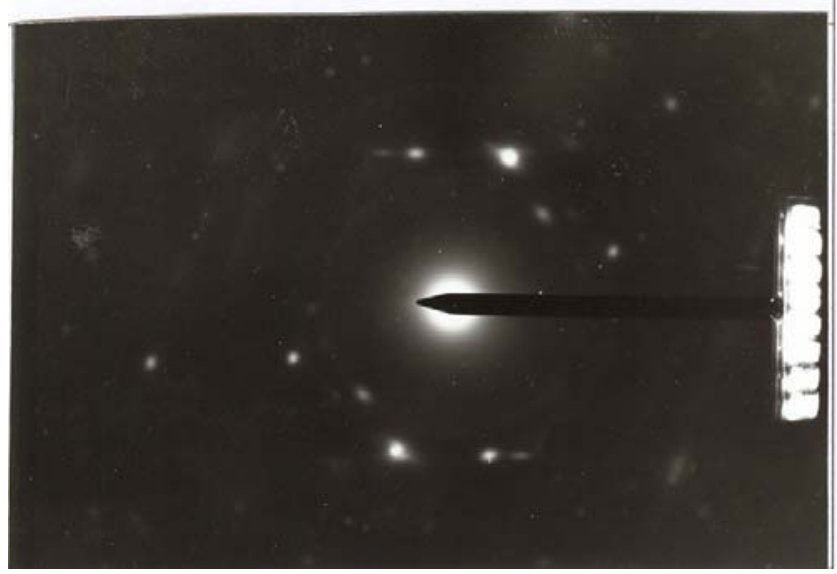

Fig.12 Diffraction electron image associated to the micro aria in Fig.11

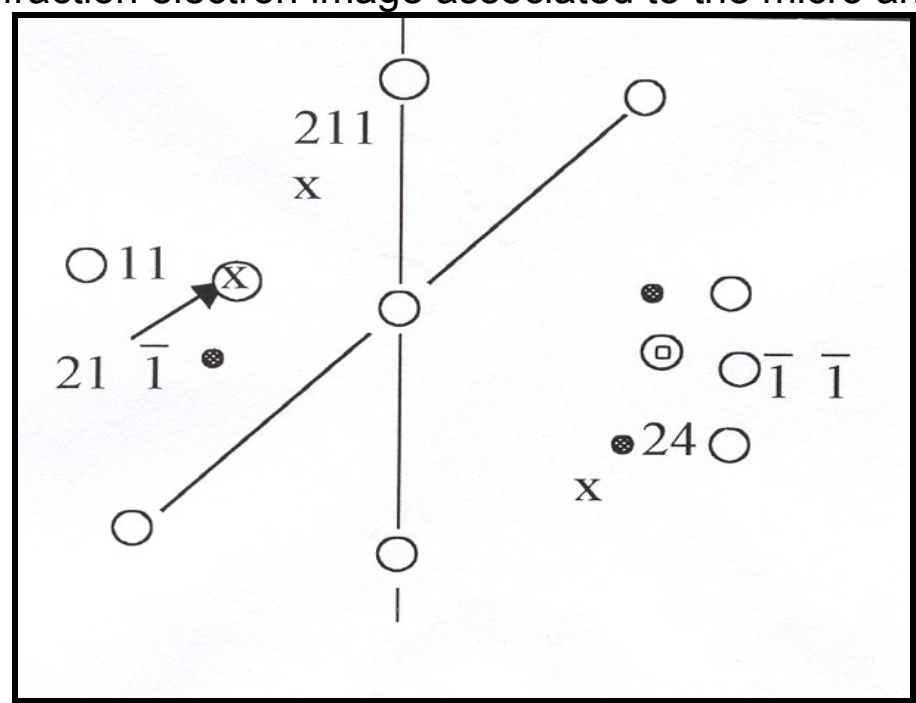

Figure 12.a.Diffraction electron image associated to the micro aria in Fig.12 o- $\alpha \mathrm{Fe}, \mathrm{zone}$ ax [311] $\quad \mathrm{x}-\mathrm{Ni}_{3} \mathrm{Mo}$, orthorhombic[120] o- SIGMA phase[211] 


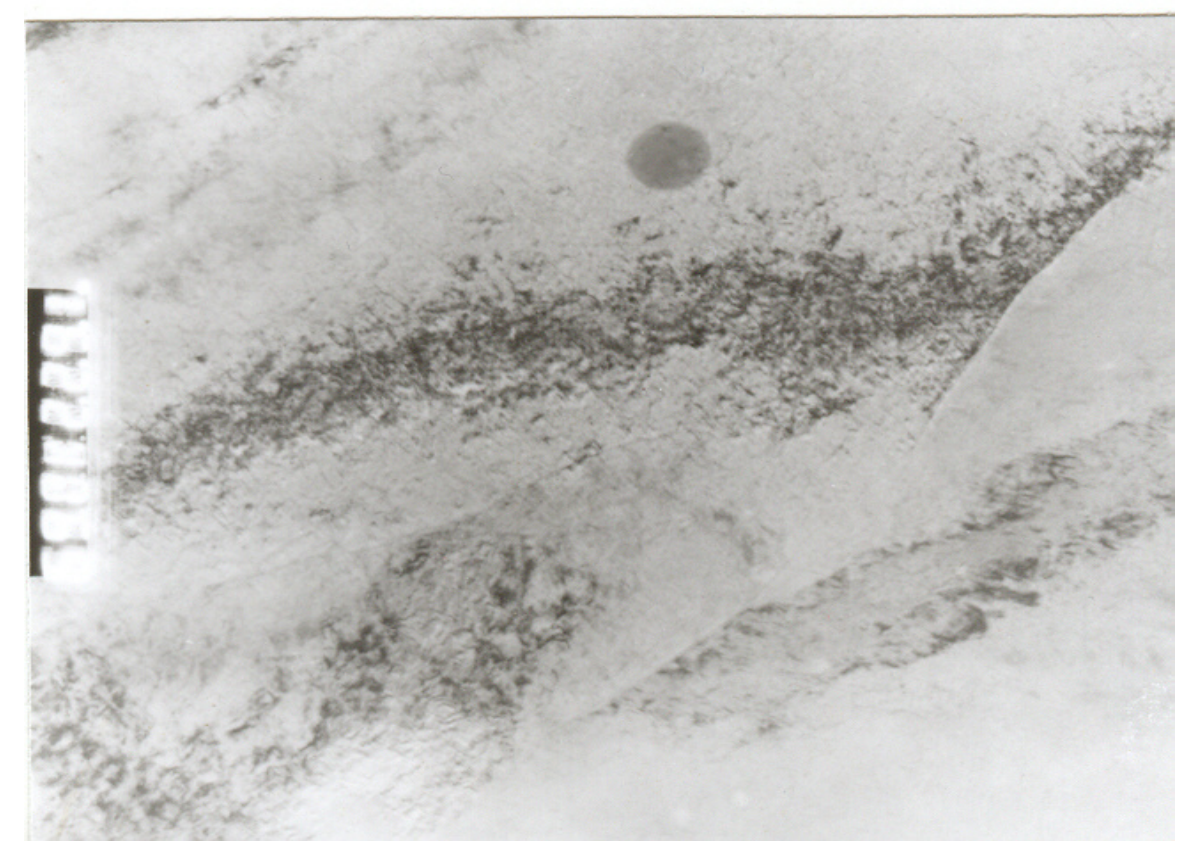

Fig.13 TEM image in luminescent field 120000:1

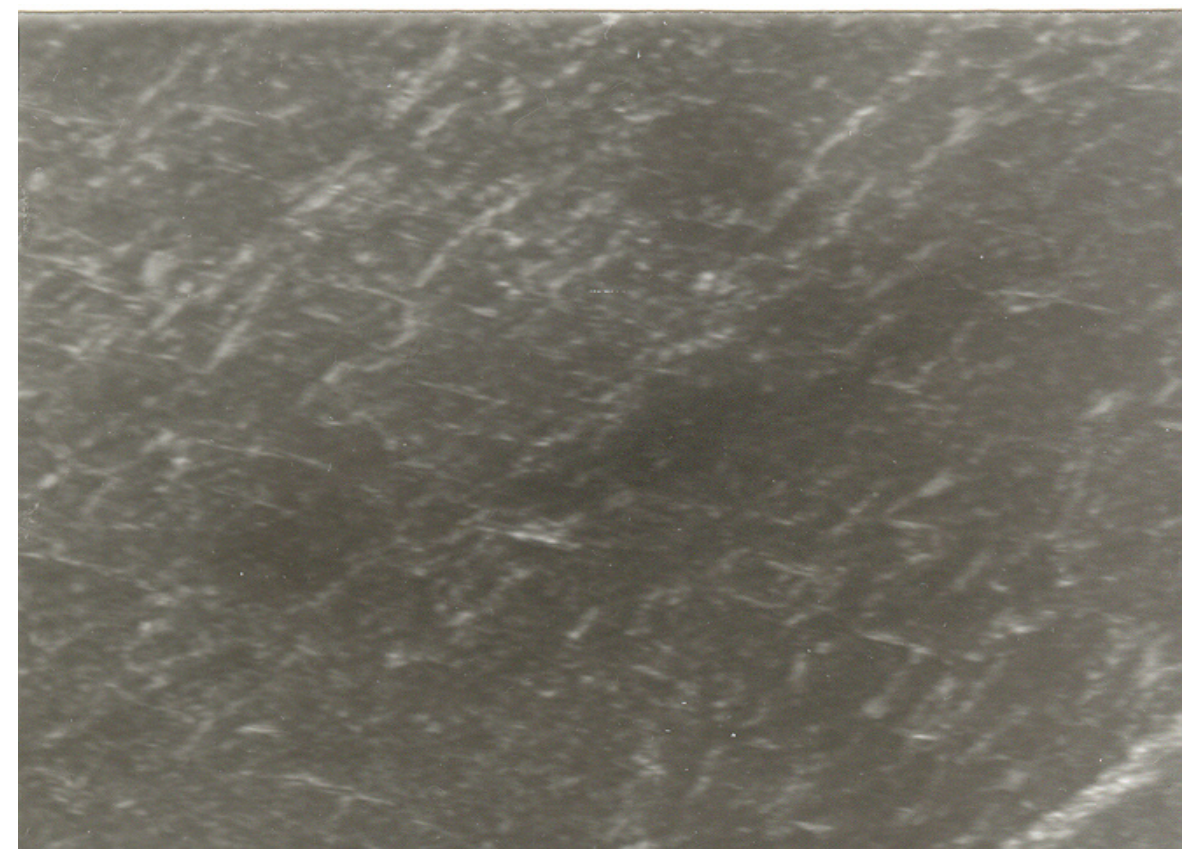

Fig.14 TEM image in dark field 120000:1-Ni 3 Mo precipitates 
